\title{
Lugar e tempo: Bento Rodrigues no Lampião
}

\section{Karina Gomes Barbosa}

Doutora; Universidade Federal de Ouro Preto; Mariana, MG, Brasil

karina.barbosa@gmail.com

\section{André Luís Carvalho}

Doutorando; Universidade Federal de Ouro Preto; Mariana, MG, Brasil

adlcarvalho@gmail.com

\begin{abstract}
Resumo
Buscamos investigar como se deu a presença de Bento Rodrigues, subdistrito de Mariana (MG), no jornalismo local marianense antes do rompimento da Barragem do Fundão em 5 de novembro de 2015, que o devastou, e se - e como - tal presença se alterou depois da catástrofe. Nosso objeto de pesquisa é o jornal Lampião, que carrega a dupla característica de jornalismo local e de jornalismo experimental. O corpus pesquisado é composto pelas 21 edições anteriores à tragédia da 0 à 20 - e pela edição 21 , dedicada ao acontecimento. A partir de análise de conteúdo, trabalhamos com as variáveis de inferência de espaço e tempo para demarcar presenças e ausências do Bento como lugar; articular as temporalidades engendradas pela cobertura do veículo; e refletir sobre as noticiabilidades acionadas pelo jornal para trazer o subdistrito à tona ou interditar sua existência midiática, nessa dupla inscrição local-experimental. A análise nos permite concluir que o passado de Bento no jornal foi determinado pela mineração, que também consolida um presente que demarca a presença da ausência, amarrando os tempos midiáticos desse lugar/não lugar.
\end{abstract}

\section{Palavras-chave}

Bento Rodrigues. Jornalismo local. Lampião. Lugar. Tempo.

\section{Vestígios}

Quando, em 5 de novembro de 2015, a lama da barragem de rejeitos da atividade minerária do complexo da empresa Samarco (controlada pela mineradora brasileira Vale e pela mineradora anglo-australiana BHP Billiton) devastou o subdistrito de Bento Rodrigues, em Mariana, interior de Minas Gerais, o jornal Estado de Minas (EM) noticiou na manchete do dia seguinte: "Barragem se rompe e tsunami de lama arrasa vilarejo"; no texto de apoio, 
Bento foi chamado de "povoado" (Figura 1). Dois dias depois, em 8 de novembro de 2015, surgiu pela primeira vez uma imagem que não era ruína: uma fotografia aérea de Bento Rodrigues, feita pelo fotógrafo Marcelo Pinheiro, tendo a Barragem de Fundão em segundo plano, sem data, mas tirada antes da tragédia (Figura 2). A chamada diz - mas não mostra: "Havia uma capela, uma escola, um posto de saúde, dezenas de casas... NÃO HÁ MAIS NADA". Na linha fina lemos: "Como, em minutos, um vilarejo centenário foi varrido do mapa". Aos poucos, o jornal mineiro foi construindo sua versão "do Bento", o subdistrito ${ }^{1}$ pertencente ao distrito de Camargos ou ao de Santa Rita Durão².

No dia 19 de novembro, Bento ressurge sem a lama que dominava as capas do jornal há 13 dias: a fachada de uma casa. A imagem foi capturada a partir do Google Street View ${ }^{3}$; por isso o crédito, Google, e as setas características da navegação do aplicativo nos cantos inferiores da imagem (Figura 3). A presença de Bento Rodrigues no EM, mais tradicional jornal de referência mineiro, se constitui de vestígios, mais que de uma marcação de presença. É compreensível/justificável dadas as características do jornalismo de referência brasileiro. Como jornal, o Estado de Minas tem de cobrir todo o vasto território mineiro com seus 853 municípios; focaliza sua cobertura nos centros econômicos mais importantes e no que orbita a região metropolitana da capital, Belo Horizonte. Mesmo considerado o mais tradicional jornal de Minas Gerais, o EM vem perdendo participação no mercado estadual. Entendemos tradição, aqui, no sentido apontado por Varão (2009): “qualquer coisa que seja transmitida ou legada como herança do passado ao presente, sob quaisquer formas: material ou simbólica, oral ou escrita" (VARÃO, 2009, p. 235); o EM, nesse contexto, é consolidado como "elemento da cultura" (VARÃO, 2009) do jornalismo mineiro e do jornalismo mineiro perante o resto do país, seja por sua perenidade, relevância, tamanho, credibilidade ${ }^{4}$.

Nesse contexto, "Bento", antes de ser tomado pelo acontecimento que o destruiu, era um ponto pequeno demais para caber na noticiabilidade do EM; para que o jornal tivesse fotos do subdistrito em seu acervo - essa hipótese parte do fato de nunca terem publicado uma imagem própria de arquivo de antes da tragédia, diante de ausência de referências visuais específicas; para que o jornal o mapeasse no território marianense.

\footnotetext{
Divisões administrativas dos distritos dos municípios mineiros com fins de descentralização administrativa, de acordo com a Lei Complementar 37, da Assembleia Legislativa de Minas Gerais (MINAS GERAIS, 1995).

2 No site da Prefeitura de Mariana Bento Rodrigues está designado como pertencente aos dois distritos (MARIANA, 2019).

3 Segundo o próprio site, o Google Street View permite que o usuário "[...] explore pontos de referência internacionais, descubra maravilhas da natureza e entre em locais como museus, locais de espetáculos e pequenas empresas.” (GO0GLE MAPS, [2018], doc. não paginado), por meio de exploração visual de paisagens em $360^{\circ}$. 0 aplicativo pode ser acessado via navegador, no computador, e em celulares com sistemas operacionais Android e IOS.

4 A edição impressa do jornal O Tempo circula mais que o EM desde 2015, assim como as dos populares Super Notícia e Aqui (a partir das edições consolidadas de DF, MG, MA e PE), segundo dados do Instituto Verificador de Circulação (IVC) referentes a 2016. No digital, o EM ainda tem mais acessos que 0 Tempo.
} 
Figura 1 - Capa do EM de 6/11/2015, um dia após o rompimento

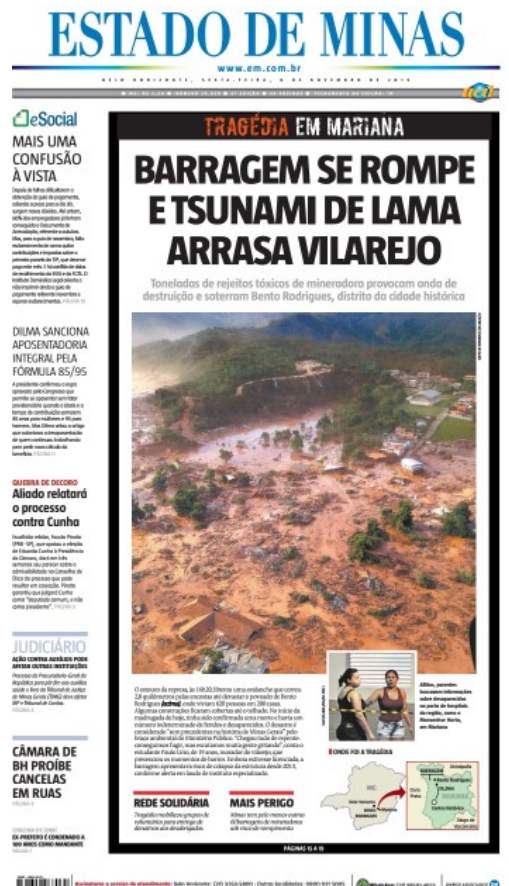

Fonte: Portal do jornal Estado de Minas.

Figura 2 - Capa do EM de 8/11/2015; na parte superior a foto aérea de Bento
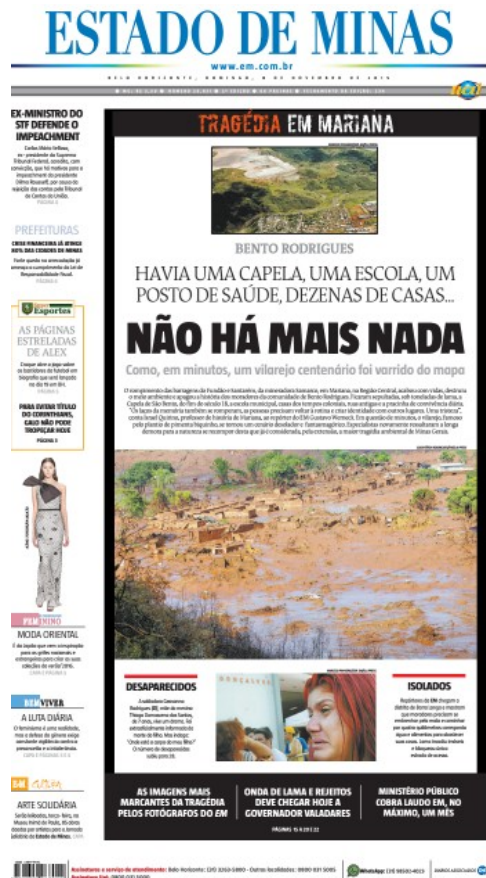

Fonte: Portal do jornal Estado de Minas. 
Figura 3 - Capa do EM de 19/11/2015; no meio da página a foto do Google Street View

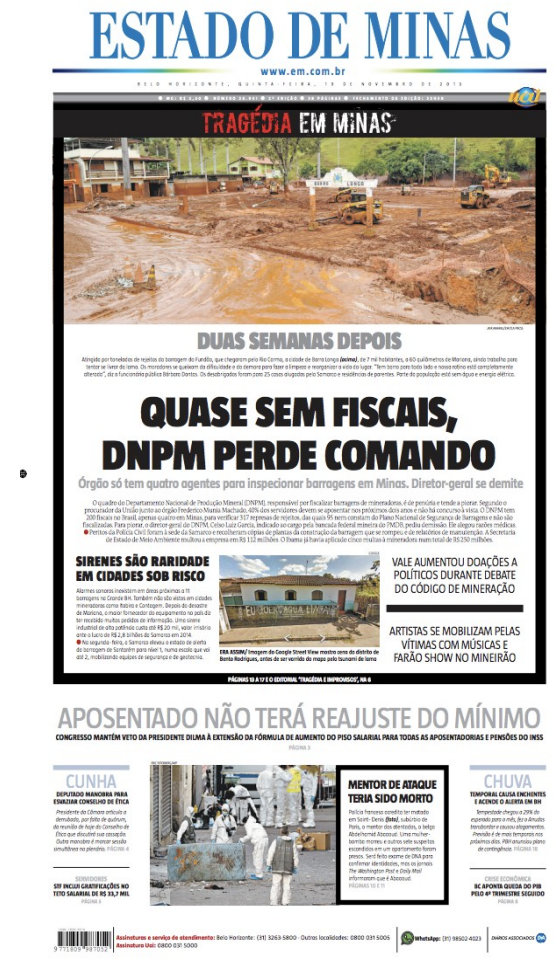

Fonte: Portal do jornal Estado de Minas.

Bento Rodrigues, então subdistrito tricentenário de Mariana, primeira cidade mineira, tinha cerca de 600 pessoas quando foi destruído pela lama da Samarco. Dadas essas dimensões, sua existência jornalística possivelmente estaria mais demarcada no jornalismo local, mais afeito à cobertura de pequenas comunidades, entendendo comunidade no sentido contemporâneo, apontado por Agnes Heller (2016), de “[...] uma unidade estruturada, organizada, de grupos, dispondo de uma hierarquia homogênea de valores [...]" (HELLER, 2016, p. 104). A essas comunidades o indivíduo não pertence obrigatoriamente, como nas comunidades naturais, mas escolhe pertencer, conforme Heller (2016): “[...] tratase de uma comunidade construída, livremente escolhida." (HELLER, 2016, p. 112, grifo da autora), tecida, de acordo com Bauman (2003), “[...] de biografias compartilhadas ao longo de uma história duradoura e uma expectativa ainda mais longa de interação freqüente [sic] e intensa." (BAUMAN, 2003, p. 48); um “entendimento comum” (BAUMAN, 2003, p. 19) realizado.

É a partir desse contexto que, neste artigo, buscamos investigar como se deu a presença de Bento Rodrigues no jornalismo local experimental marianense antes do rompimento da barragem e se - e como - tal cobertura se alterou após o colapso da estrutura. Então indagamos: este jornalismo realiza sua característica experimental ou repete padrões de noticibilidade do jornalismo de referência? Há espaço para lugares como 
Bento nessas práticas locais experimentais ou apenas para acontecimentos como o rompimento da barragem - que evocam, então, inevitavelmente, Bento? Nosso objeto de pesquisa é o jornal Lampião, que carrega a dupla característica de jornalismo local e de jornalismo experimental. Nossa atenção se volta para as dimensões espaço-temporais da presença de Bento no Lampião, a partir de discussões acerca das ideias de lugar e tempo, tão centrais, a nosso ver, ao jornalismo local. Nosso objetivo central foi perceber de que maneira o jornalismo local experimental constrói os lugares que lhe dizem respeito midiaticamente construção esta atravessada e entrelaçada por uma temporalidade marcada pela ruptura advinda da catástrofe e do trauma.

Para empreender esta tarefa, realizamos análise de conteúdo a partir de levantamento quantitativo nas 21 edições do jornal Lampião antes do rompimento - da edição 0 à edição 20 - em busca de indicadores da presença de Bento Rodrigues e dos outros distritos marianenses e ouro-pretanos. Atestada a presença do Bento, detivemo-nos nas matérias jornalísticas (descartamos, portanto, a seção de opinião, na página dois) para então realizar inferências de conhecimentos (BARDIN, 2004) a partir de variáveis extraídas dos textos selecionados. A pesquisa documental foi realizada de modo a selecionar o material de pesquisa; posteriormente, classificar o material (a partir da qualidade das menções, como veremos à frente); para, então, trabalhar com variáveis de inferência relacionadas a Bento. Também analisamos qualitativamente as edições produzidas pelo Lampião ao longo de 2016, ou seja, no primeiro ano posterior ao rompimento.

A escolha pelo Lampião parte do papel do jornal no panorama da mídia local. Mesmo sendo produzido no âmbito da universidade, é um veículo que se diferencia dos demais produzidos e circulantes na cidade porque não possui filiações políticas e/ou econômicas; tem as rotinas produtivas mais bem estabelecidas e as maiores equipes, enquanto outros jornais são produzidos por equipes bastante reduzidas e, eventualmente, não possuem redações ou rotinas jornalísticas delimitadas, como reuniões de pauta; possui conteúdo mais alinhado às características do jornal impresso (GROTH, 2011), identificados mais claramente como jornalísticos ${ }^{5}$. Mariana não possui nenhum jornal diário; o veículo mais vendido é o Ponto final, semanário em geral de 12 páginas produzido majoritariamente por estagiários do curso de Jornalismo da Universidade Federal de Ouro Preto (Ufop) e com mescla de conteúdos jornalísticos, releases, artigos opinativos e coluna social. Circulam ainda pela cidade jornais de regiões próximas, como Ouro Preto, e publicações de caráter publicitário,

\footnotetext{
5 Ribeiro (2010) comenta acerca da imprensa regional portuguesa que trata-se de "Uma imprensa que na generalidade tem uma baixa tiragem em virtude de atingir apenas um pequeno território, estruturas semi-amadoras e pouco poder económico que leva em geral a um nível baixo de qualidade." (RIBEIRO, 2010, p. 25). Essa avaliação aplica-se muito apropriadamente ao panorama jornalístico comercial de Mariana, mais próximo do jornalismo pré-industrial que do jornalismo industrial e bastante distante do jornalismo pós-industrial.
} 
religioso, cultural. Entre eles estão O Liberal, Folha Marianense, $O$ Espeto, $O$ Mundo dos Inconfidentes e Jornal Pastoral.

Voltar nosso olhar para o acontecimento que rasgou a cidade de Mariana, o subdistrito de Bento Rodrigues, o Rio Doce, uma série de locais ao longo do trajeto percorrido pela lama, e deixou 19 mortos (um desaparecido), justifica-se ainda dada a dimensão ambiental do rompimento da barragem de Fundão. Mas não apenas. Suas características sociais pulsam no contexto atual da cidade e reverberam no jornalismo local e na universidade.

\title{
2 Distritos
}

o Lampião surgiu em 2011, no terceiro ano de existência do curso de Jornalismo da Universidade Federal de Ouro Preto (Ufop), como parte da antiga matriz curricular do curso e exigência de veículos laboratoriais nos cursos de Jornalismo nas diretrizes curriculares nacionais (então em vigor), dentro da disciplina Laboratório de Impresso I - Jornal ${ }^{6}$. Era, então, ofertado no sexto semestre ${ }^{7}$ do curso, por professores das áreas de texto e planejamento visual - logo nas primeiras edições houve o acréscimo do professor de fotografia. Já no editorial de sua edição 0, de maio de 2011, o jornal-laboratório afirma se dirigir “[...] à cidade de Mariana [e se mostra preocupado com a] [...] construção de um lugar melhor [a partir de um jornalismo produzido por pessoas] [...] que circulam pela cidade, que ocupam os mesmos espaços num mesmo tempo e compasso." (OUTRO..., 2011, p. 2).

A missão do jornal, apresentada aos estudantes nas primeiras aulas, quando o projeto editorial é explicitado, é a seguinte:

\begin{abstract}
Ser um veículo de comunicação e informação que promove o elo entre a universidade e a sociedade, voltado para Mariana e Ouro Preto. Apresenta uma linha editorial que eleva o contexto para além do campus universitário, não atendendo a outros interesses que não os da comunidade, assumindo, assim, um compromisso de serviço ao leitor. (SANTOS; GOMES BARBOSA; AQUINO, 2016, p. 18).
\end{abstract}

Na mesma linha, o perfil editorial demarca claramente o veículo como jornal local das cidades de Mariana e Ouro Preto (onde está o campus com a maior quantidade dos cursos da

\footnotetext{
${ }^{6}$ O projeto pedagógico do curso de Jornalismo, atualmente com 22 professores que atuam nas áreas de texto, fotografia, teoria, audiovisual, planejamento visual, rádio, web e assessoria, prevê uma formação "humanística e profissional sólida [preparando] [...] jornalistas competentes do ponto de vista técnico, ético e estético" (UFOP, 2015, p. 20). 0 texto ressalta a necessidade de formação crítica, "sempre atenta a questões políticas e temáticas contemporâneas, para atuar junto à sociedade, comprometidos com a cidadania" (UFOP, 2015, p. 20). As menções a um jornalismo crítico e cidadão aparecem com bastante força no perfil desejado do egresso, assim como a atenção e o respeito à ética e às normas deontológicas da profissão.

7 No segundo semestre de 2013, a disciplina passa a ser ofertada no quinto período do Curso.
} 
Ufop), logo a partir das primeiras edições. É um “[...] jornal a serviço da comunidade: se coloca como transformador da realidade na medida em que reflete e aprofunda os conflitos, as necessidades e as memórias dos cidadãos, a dinâmica urbana e o desenvolvimento local, com reflexos na vida de seus habitantes." (SANTOS; GOMES BARBOSA; AQUINO, 2016, p. 17).

Na edição 12, o jornal passa a contar com a editoria Distrito, a partir do diagnóstico da turma e dos professores à frente da disciplina de que a cobertura do Lampião estava excessivamente centrada nos distritos-sede de Mariana e Ouro Preto, sem muitas vezes abordar os demais que compõem esses municípios. Dali em diante, toda edição deveria contar com, pelo menos, uma pauta de algum distrito de uma das duas cidades, tornando Distrito a única editoria efetivamente fixa no projeto editorial do veículo ${ }^{8}$ - ainda que não explicitamente, essa orientação se materializava nas rotinas produtivas, desde a preparação para a reunião de pauta até o fechamento do espelho ${ }^{9}$. A obrigatoriedade de abordar os distritos parece, portanto, indicar uma preocupação em delimitar o lugar que este jornalismo local reporta e ao qual se refere; lugar ao qual pertence e o que autoriza pertencer nesse lugar jornalisticamente construído. Esse lugar inclui, diz-nos tal decisão editorial, também os distritos das duas cidades - espaço onde se localizava Bento Rodrigues antes de 5 de novembro de 2015. A inclusão desta editoria gera uma expectativa de contrato de leitura: de que todos os distritos estarão/estariam, em algum momento, no jornal. Ainda que não houvesse nenhuma obrigatoriedade explícita de que todos os distritos marianenses e ouro-pretanos fossem cobertos, a cobertura sistemática de distritos cria a ideia de que a totalidade dos municípios, o que inclui todos os distritos, e não apenas alguns, estejam abarcados nessa cobertura.

A edição $21\left(\mathrm{a} 22^{\mathrm{a}}\right)$, dedicada à cobertura do rompimento da barragem, transforma a relação do Lampião com os distritos das cidades e, mais destacadamente, com Bento Rodrigues, subdistrito de Mariana devastado pela lama. Por isso, nos debruçamos primeiramente sobre as edições anteriores - de 0 a 20 - para compreender como esse locus era construído jornalisticamente pelo jornal, como se integrava ao lugar delimitado jornalisticamente pelo veículo.

Nas primeiras 21 edições, o Lampião publicou 364 matérias. Em todos esses conteúdos, foram feitas 81 menções a distritos, ou 22,2\%. Classificamos as menções como simples (apenas o nome do distrito); destaques baixos (matérias em que o distrito surge com contexto mínimo); destaques médios (matérias em que o distrito é abordado em um

\footnotetext{
Na edição 29, a penúltima produzida dentro do formato da matriz antiga do curso de Jornalismo, no segundo semestre de 2017, a turma e os professores decidiram extinguir a editoria Distrito, a partir do entendimento de que a separação entre pautas de Cidade e Distrito segrega os últimos, que também integram as cidades de referência.

${ }^{9}$ Cada estudante deve propor duas pautas na reunião geral. Em reunião posterior, editores e professores escolhem as pautas a serem produzidas na edição; o espelho do jornal só é fechado se há pelo menos uma pauta de Distrito.
} 
trecho); e destaques altos (matérias em que o distrito é proeminente/o tema da matéria). 0 distrito mais abordado foi Passagem de Mariana, com 24 menções, ou 40\%. Passagem é o distrito mais próximo de Mariana; fica praticamente colado à sede e, logo, à redação do jornal-laboratório; e conecta Ouro Preto à Primaz de Minas. Dois distritos de Ouro Preto, Miguel Burnier e Engenheiro Corrêa, não haviam aparecido no Lampião ${ }^{10}$. A predominância absoluta de distritos abordados diz respeito aos que pertencem a Mariana - 63 menções. 0 distrito mais abordado de Ouro Preto é Antônio Pereira, com cinco menções. Antônio Pereira fica mais próximo ao centro de Mariana $(11,1 \mathrm{~km})$ que do de Ouro Preto $(25,5 \mathrm{~km})$. Com exceção da edição 1, o Lampião aborda algum distrito em todos os números, em geral, no Especial (reportagem mais extensa, nas páginas 6 e 7 do jornal) ou em Distrito ${ }^{11}$. De todas as menções, apenas 35\% se tratam de destaques altos dos distritos. Outros $40 \%$ se tratam ou de menções simples - 26,7\%, ou de destaques baixos - 13,3\%. A maioria das matérias que trazem distritos, 53,3\%, ouve entre uma ou três fontes do distrito, mas não traz fotos $(43,3 \%)^{12}$. Essa falta de marcações testemunhais e, especialmente, imagéticas é mais um sintoma da forma como o veículo cobre os distritos no jornalismo local que efetiva, ao não apresentá-los visualmente ao leitor; ao dedicar-lhes menos espaço e atenção.

\section{Bento}

0 primeiro indício de Bento Rodrigues no Lampião surge em uma menção simples na página 9 da edição 3 (Figura 4), em matéria sobre as obras no aterro sanitário de Mariana. "O aterro está localizado a cerca de oito quilômetros do centro da cidade, na estrada de acesso ao subdistrito de Bento Rodrigues" (SENA, 2011, p. 9) (Figura 5). Aqui, Bento é apenas um ponto de referência em um caminho/um trecho do percurso no mapa; serve para localizar o leitor a respeito de outro assunto; para levar o leitor a outro lugar; não é sobre Bento que a matéria se debruça. Bento surge como em um mapa; apenas demarca, conforme Certeau (1998). A menção a Bento o torna um "lugar geográfico" (CERTEAU, 1998,

\footnotetext{
${ }^{10}$ Miguel Burnier foi tema de reportagem na edição 23 e manchete na edição 27.

${ }^{11}$ Nas edições 5, 9 e 13 o Especial tem presença mais forte dos distritos. 0 tema do especial da edição 5 foram movimentos artísticos, com destaque para a efervescência cultural de Passagem. 0 especial do número 9 trata das tradições de alguns distritos: Cláudio Manoel, Furquim, Passagem, Camargos e Cachoeira do Brumado. Na edição 13, o tema é o Ribeirão do Carmo, que percorre todo o município; há destaques baixos e uma matéria que enfoca uma personagem de Passagem.

${ }^{12}$ Um fator, que não será aprofundado neste trabalho, que pode contribuir para a baixa cobertura de distritos realizada pelo Lampião refere-se à estrutura produtiva do jornal, transformada após o rompimento da barragem. 0 deslocamento demandava gastos por parte dos estudantes (muitos de baixa renda), com valor alto de passagens e rede de transporte público municipal deficiente. 0 contexto se agravava no caso de distritos mais distantes da sede. Com a tragédia, os dois veículos laboratoriais do curso de Jornalismo passam a contar, depois de gestão junto à reitoria da Ufop, com carros da universidade para realizar a cobertura jornalística do acontecimento de maneira minimamente satisfatória para cumprir o aprendizado e também o papel social do jornalismo. Entre novembro de 2015 e fevereiro de 2016, equipes de reportagem do Lampião e da revista-laboratório Curinga realizaram 15 viagens para Bento Rodrigues, Camargos e Barra Longa com veículos oficiais da Ufop. A logística de transportes tem se mantido desde então.
} 
p. 215) isolado em um mapa ou em um percurso - do qual sequer é o destino final. Como diz Certeau, os nomes de um itinerário (Bento no caminho) criam não-lugares em relação a um lugar (o aterro); transformam os não-lugares em passagens.

Figura 4 - Primeira menção do Lampião a Bento Rodrigues, na edição 3

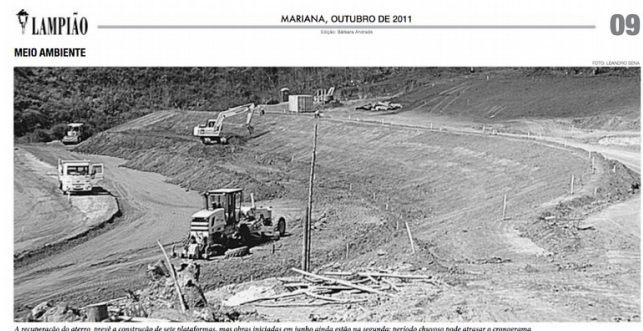

\section{Obras no aterro sanitário da cidade correm contra 0 tempo}

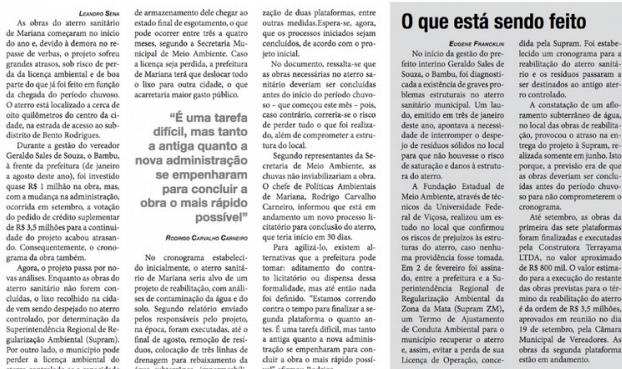

Fonte: Acervo digital do jornal Lampião no Issuu.com.

Figura 5: detalhe do subdistrito como percurso.

\section{O aterro está localizado a cerca de oito quilômetros do centro da ci- dade, na estrada de acesso ao sub- distrito de Bento Rodrigues.}

Fonte: Acervo digital do jornal Lampião no Issuu.com.

O Lampião só volta a mencionar Bento Rodrigues na edição 16, não mais como indício, e sim como lugar com existência material. A matéria Do plantio aos resultados (Figura 7) aborda a associação de cultivo e beneficiamento de pimenta biquinho formada por mulheres do lugar, Associação de Hortigranjeiros de Bento Rodrigues (Ahobero). A demarcação do lugar já começa no sutiã: "Associação de Bento Rodrigues investe em produto artesanal; mulheres ganham independência financeira" (MANDARINO, 2014, p. 9). Prossegue no lide: "Algumas pessoas que vão a Bento Rodrigues, distrito de Mariana, podem não saber que nesse pequeno lugarejo existe uma associação quase toda feminina que trabalha na fabricação de geleia artesanal à base de pimenta biquinho." (MANDARINO, 2014, p. 9). 0 
subdistrito surge, nesta edição, inclusive com destaque na capa do jornal (Figura 6). Aqui, Bento deixa de ser um ponto no caminho do lixo para ganhar existência; como distrito (sic) [subdistrito]; lugarejo; lugar de plantio, produção e morada. Mas para além de demarcar tal lugar, parece haver aqui uma indicação de relato; de travessia (CERTEAU, 1998, p. 215). Nessa presença de Bento, o relato jornalístico ajuda na feitura de um espaço (CERTEAU, 1998).

Figura 6 - Capa da edição 16 do Lampião com menção a Bento na capa

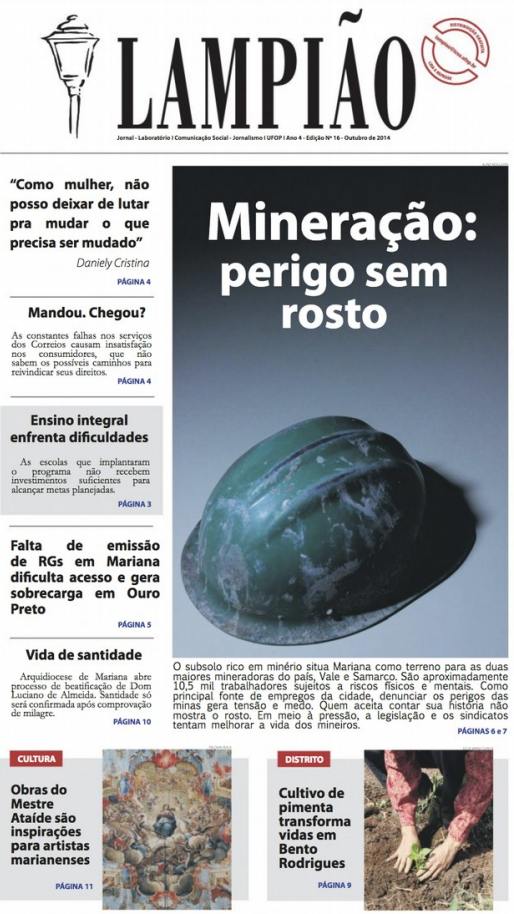

Fonte: Acervo digital do jornal Lampião no Issuu.com.

Figura 7 - Reportagem do Lampião sobre o plantio de pimenta biquinho

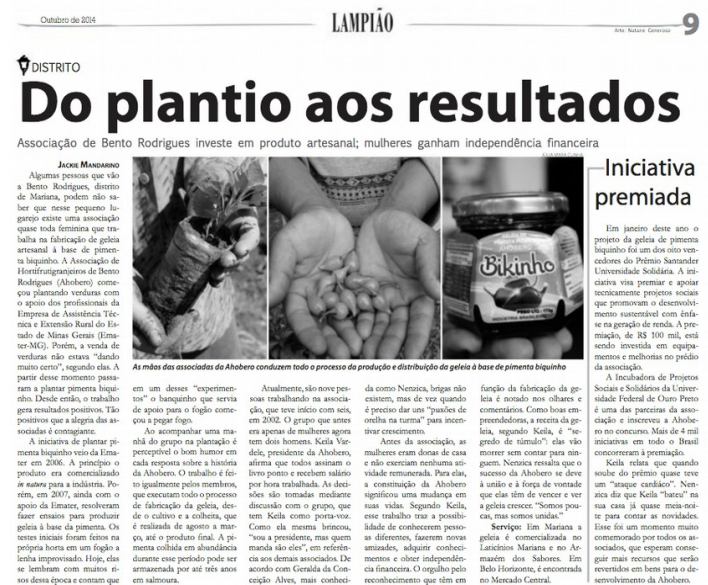

Fonte: Acervo digital do jornal Lampião no Issuu.com. 
Na edição seguinte, 17, Bento Rodrigues é mencionado na matéria Turismo requer atenção (NOGUEIRA, 2014, p. 3) a respeito de um destino turístico que a Prefeitura de Mariana, à época (dezembro de 2014), queria revitalizar, chamado Estrada Parque: Caminhos da Mineração, previsto, premonitória e fatidicamente, para o ano seguinte (Figura 8). “De acordo com Lívia Duarte, a iniciativa visa reconstruir os distritos de Bento Rodrigues, Camargo e Santa Rita Durão de forma mais atrativa, com restaurantes, hotéis e opções mais diversificadas de visitação com guias capacitados" (NOGUEIRA, 2014, p. 3), diz o trecho. Essa é a única menção no texto.

O último vestígio de Bento Rodrigues no Lampião antes de 5 de novembro de 2015 ocorre na edição 19, em matéria sobre projeto educacional em distritos (Figura 9). Tratavase do projeto Cidadão do Futuro, da Samarco, “[...] presente nos distritos de Antônio Pereira (Ouro Preto), Bento Rodrigues (Mariana) e em Brumal (Santa Bárbara), localidades próximas às unidades industriais da empresa." (OLIVEIRA, 2015, p. 5). A reportagem foca na atuação do projeto em Antônio Pereira.

Figura 8 - Trecho da reportagem sobre turismo na edição 17 do Lampião, em que Bento é

$$
\begin{aligned}
& \text { mencionado } \\
& \text { A fim de incentivar o ecoturis- } \\
& \text { mo e incluir os distritos nas rotas tu- } \\
& \text { risticas, a Prefeitura de Mariana está } \\
& \text { estruturando o projeto Fstrada Par- } \\
& \text { que: Caminhos da Mineraçăo, que } \\
& \text { deve começar em } 2015 \text {. De acor- } \\
& \text { do com Livia Duarte, a iniciativa } \\
& \text { visa reconstruir os distritos de Ben- } \\
& \text { to Rodrigues, Camango e Santa Rita }
\end{aligned}
$$

Fonte: Acervo digital do jornal Lampião no Issuu.com.

Figura 9 - Trecho da reportagem sobre educação na edição 19 do Lampião com a menção ao subdistrito

$$
\begin{aligned}
& \text { Programa } \\
& \text { O Cidadão do Futuro é um } \\
& \text { programa da Samarco em par- } \\
& \text { ceria com o Instituto Parami- } \\
& \text { tas, com a intenção de trans- } \\
& \text { formar a cidadania por meio } \\
& \text { da valorização da cultura local } \\
& \text { e de ações com foco em edu- } \\
& \text { cação por meio do uso de tec- } \\
& \text { nologias da informação. } \\
& \text { A iniciativa está presen- } \\
& \text { te nos distritos de Antônio } \\
& \text { Pereira (Ouro Preto), Ben- } \\
& \text { to Rodrigues (Mariana) e em } \\
& \text { Brumal (Santa Bárbara), loca- } \\
& \text { lidades próximas às unidades } \\
& \text { industriais da empresa. }
\end{aligned}
$$

Fonte: Acervo digital do jornal Lampião no Issuu.com.

Das quatro menções a Bento, duas estão diretamente ligadas à mineração, marca que também dita o destino do subdistrito quando ele desaparece - e o que o faz reaparecer no 
jornal; motivo que aparenta determinar a presença jornalística do subdistrito. Antes do colapso da barragem do Fundão, a mediação feita pela mineração é da riqueza, do ouro, da atividade que gera receita, turismo e melhorias para a cidade. Após 5 de novembro, é a face mais sombria de uma das atividades laborais mais inseguras do mundo que surge para mediar essa presença. 0 destino turístico citado na edição 17 buscava percorrer localidades de Mariana conectadas à exploração minerária, possivelmente ampliando o potencial de locais como a Mina de Passagem ${ }^{13}$. Já o projeto educacional da Samarco, Cidadão do Futuro, era realizado em Bento Rodrigues e em outros pontos como compensação legal obrigatória devido à atividade da mineração, que deteriora as áreas exploradas.

A mineração, assim, surge quase como determinante da noticiabilidade para possibilitar a presença de Bento Rodrigues no jornalismo local praticado pelo Lampião. Conforme aponta Gislene Silva, noticiabilidade se refere a "[...] todo e qualquer fator potencialmente capaz de agir no processo de produção da notícia [...]" (SILVA, 2014, p. 52); no caso específico, relacionado tanto à origem como à visão dos fatos - sobretudo no que concerne ao que o Lampião compreende como o interesse público marianense.

Uma das menções a Bento no Lampião reifica o subdistrito como ponto de referência rumo a outro lugar, este sim com existência material. Nesse caso, Bento tem menos concretude que o lixão da cidade. É apenas na matéria sobre a pimenta biquinho que Bento Rodrigues ganha alguma existência autônoma - ainda que seja erroneamente classificado pela reportagem, ato indicador da desimportância do lugar para o jornal (como o é para o $E M)$, ao não demarcar corretamente o status de subdistrito.

A partir dessas pistas, o Bento Rodrigues que emerge é um distrito ou subdistrito que está no caminho do lixão, integra o percurso minerário da cidade, recebe projetos educacionais e promessas políticas de melhoria no turismo - com a esperança de uma ironia posterior, inclusive, de reconstrução. É um "pequeno lugarejo" (MANDARINO, 2014, p. 9), com hortas para plantio da pimenta biquinho. A imagem de vilarejo, povoado ou comunidade rural, que foi construída pelo Estado de Minas após o rompimento, é a mesma construída pelo Lampião antes da catástrofe, reforçada por informações como a de que os primeiros testes para produzir a geleia foram feitos em um fogão a lenha improvisado pelas mulheres da associação; ou a de que antes de produtoras rurais eram donas de casa sem atividades remuneradas. São pistas tão esparsas que urge questionar: o Bento que o Lampião construiu chega a ser um lugar?

\footnotetext{
${ }^{13}$ Maior Mina de Ouro aberta a visitação do mundo, segundo o site do local. O destino turístico fica na entrada de Mariana, no caminho para Ouro Preto (MARIANA, 2018).
} 


\section{Lugar}

O jornalismo local, ou de proximidade, se alicerça nas ideias de lugar e de comunidade, conforme destaca Érik Neveu (2006): "A particularidade do jornalismo local é sobretudo a relação de proximidade que ele mantém com suas fontes e seus leitores." (NEVEU, 2006, p. 56). Mais à frente, o autor lembra que esse tipo de jornal define seus leitores "pelo pertencimento a um território" (NEVEU, 2006, p. 56). Beatriz Dornelles (2006) define assim um dos tipos de jornais locais:

[...] contribuir para a ampliação da cidadania e favorecer a participação popular; ocupando-se com questões relativas às desigualdades e aos movimentos sociais; às vezes desempenham papéis que extrapolam as funções tradicionais de um jornal, colocando-se como agente de cobrança e no papel de protagonista na solução de um problema social. (DORNELLES, 2006, p. 172).

Esse tipo não é marcado pelo viés comercial que explora o local como nicho de mercado, mas tem, de acordo com Dornelles, certas características daquele. Elencamos algumas enumeradas pela autora: dá cobertura aos acontecimentos locais, com a abordagem de assuntos diretamente sintonizados com a realidade local, que em geral não têm espaço na grande mídia, pode ser identificado como um reprodutor da lógica dos grandes meios de comunicação (DORNELLES, 2006, p. 172).

Mas como se definem os lugares a que se reporta, e que reporta, o jornalismo local? Marc Augé (1994) nos lembra que o lugar é uma "cultura localizada no tempo e no espaço" (AUGÉ, 1994, p. 36), com fronteiras sempre demarcadas (AUGÉ, 1994, p. 43). Falando dos indígenas, mas em um comentário que bem pode ser expandido para cidades de interior e comunidades como as que o Lampião reporta, Augé explica que o “[...] dispositivo espacial é, ao mesmo tempo, o que exprime a identidade do grupo (as origens do grupo são, muitas vezes, diversas, mas é a identidade do lugar que o funda, congrega e une) [...]" (AUGÉ, 1994, p. 45). Assim, os lugares, para os grupos sociais que o integram, são parte do que motiva e molda práticas coletivas e individuais.

Em linha similar, Certeau (1998) pensa o lugar como composto de estratos partilhados, permeados por deslocamentos e efeitos; são "histórias fragmentárias e isoladas em si" (CERTEAU, 1998, p. 189). "Um lugar é a ordem (seja qual for) segundo a qual se distribuem elementos nas relações de coexistência." (CERTEAU, 1998, p. 201, grifo do autor) diz, mais adiante, ao reforçar que o lugar indica estabilidade. Tal lugar, praticado, se torna 
espaço; um conjunto de sistemas reais percorridos por passos, relatados. A relação, fundamental, portanto é com a prática e com a experiência.

Pelos vestígios no Lampião, Bento não se tratava de um espaço praticado, uma vez que mal é percorrido por esse jornalismo/pelos jornalistas que o integram; mas também o veículo mal reporta as coexistências e as culturas localizadas num tempo e espaço que ali existiam. Para além da demarcação cartográfica, o Lampião não dá existência jornalística ao lugar Bento Rodrigues em suas páginas. Se o que o Lampião pratica é jornalismo local, feito, portanto, de lugares, comunidades e proximidades, e Bento é ausente deste jornalismo - e inexistente como lugar -, depreendemos uma interdição à existência de Bento como lugar que o Lampião cobre, ao qual se reporta. Bento fica, também, de fora do “'nós' territorializado" a que se refere Neveu (2006, p. 57).

Essa ausência/interdição revela uma desimportância jornalística do subdistrito. 0 cotidiano de Bento, sua comunidade, seus pontos turísticos, suas festas, cachoeiras, a barragem que o ameaçava silenciosamente, nunca foram considerados noticiáveis pelo Lampião em 21 edições, ao longo de quatro anos. 0 que nos traz de volta à questão da noticiabilidade. Na concepção de Gislene Silva, a origem dos fatos compreende uma das esferas da noticiabilidade. É onde se encontram os valores-notícia em si, os atributos que orientam a seleção primária dos fatos - a escolha de qual "[...] acontecimento é mais merecedor de adquirir existência pública como notícia." (SILVA, 2014, p. 54). No jornalismo local, a proximidade - tanto geográfica quanto cultural - é um valor-notícia preponderante.

Desde Eça de Queirós, diversos autores indicam que é, de fato, um valor-notícia intrínseco a esse tipo de cobertura, não à toa também denominada jornalismo de proximidade:

\begin{abstract}
A mais pequenina dor que diante de nós se produza e diante de nós gema, põe na nossa alma uma comiseração e na nossa carne um arrepio, que lhe não dariam as mais pavorosas catástrofes passadas longe, noutro tempo ou sob outros céus. Um homem caído a um poço na minha rua mais ansiadamente me sobressalta que cem mineiros sepultados numa mina da Sibéria - e um carro esmagando a pata de um cão, em frente à nossa janela, é um caso infinitamente mais aflitivo do que a heróica e adorável Joana d'Arc queimada na praça de Ruão! A distância e o tempo fazem das mais grossas tragédias ligeiras notícias - onde nenhum espírito são, bem equilibrado, encontra motivo de angústia ou pranto. (EÇA DE QUEIROZ, 1979, doc. não paginado)
\end{abstract}

A Pesquisa Brasileira de Mídia também reforça o vínculo entre os leitores e as notícias locais ou próximas. 
Entre os cadernos mais lidos pelos entrevistados $\left(1^{\circ}+2^{\circ}\right.$ lugares) estão os de cidade, notícias locais e cotidiano (28\%), esportes (24\%), notícias policiais $(16 \%)$, política brasileira $(14 \%)$, classificados (12\%), cultura e lazer (10\%) e economia brasileira (10\%). (BRASIL, 2014, p. 66).

Camponez (2012) diz que, no caso de meios locais, a proximidade adquire "significado próprio, marcante da sua especificidade e da sua identidade" (CAMPONEZ, 2012, p. 36). Para Camponez (2012), uma definição de jornalismo regional - que, aqui, utilizamos para pensar também o jornalismo local - parte do conceito de “[...] pacto comunicacional realizado no contexto de comunidades de lugar - isto é, comunidades que se reconhecem com base em valores e interesses construídos e recriados localmente [...]" (CAMPONEZ, 2012, p. 36, grifo do autor). Nesse sentido, a proximidade não é mais apenas um valor-notícia, mas ganha dimensão simbólica, conforme Camponez.

Porém, como dissemos acima, a partir dos vestígios encontrados, é a mineração que guia mais fortemente a presença de Bento no Lampião antes de 5 de novembro de 2015. Nesse sentido, o subdistrito de Bento Rodrigues parece não estar abrangido no que o Lampião considera próximo, ou ao lugar a que se reporta/que reporta. 0 mapa geográfico, cultural e, acrescentamos, afetivo que compõe o local do jornalismo praticado pelo Lampião não inclui Bento; na verdade, inclui poucos distritos, mesmo diante da decisão editorial de ter uma editoria exclusivamente dedicada a eles. A mineração, principal locomotiva econômica da região, tem mais peso relacional em definir a noticiabilidade no Lampião que a proximidade.

Para além de jornalismo local ou de proximidade, o Lampião efetiva uma práxis jornalística laboratorial. Como tal, deveria distanciar-se, diferenciar-se - ou, ao menos buscar não reproduzir acriticamente - do jornalismo comercial, conforme Antônio Vieira Junior (2002). “A linguagem não é a mesma do jornal-empresa que se direciona mais ao real imediato, ou seja, ao fato acontecido em menos de 24 horas [...]" (VIEIRA JUNIOR, 2002, p. 69). Também deve "propor alternativas" (VIEIRA JUNIOR, 2002, p. 70) e criar novos modelos. Em suma, experimentar, efetivar possibilidades de jornalismo que o distingam do modelo de referência, comercial. Isso proporciona, diz Vieira Junior (2002), a formação de um profissional crítico e capacitado para operar de maneira ativa e transformadora no mercado jornalístico. Nessa perspectiva laboratorial e experimental, a noticiabilidade dos veículos produzidos por estudantes de Jornalismo deveria se distanciar, também, de alguma maneira, das noticiabilidades similares às do jornalismo tradicional. Em um veículo como o Lampião ${ }^{14}$, que se dispõe a lançar luz sobre personagens, histórias e vidas, espera-se que

\footnotetext{
${ }^{14} 0$ nome do jornal se deve a um lampião histórico instalado na Praça da Sé da cidade de Mariana. A metáfora da iluminação é recorrente na história do Lampião, sobretudo nos editoriais.
} 
essa distância se amplie e seja marcada, na medida em que esses pequenos acontecimentos, essas miudezas, costumam não ter destaque em pautas de veículos comerciais. Parte da experimentação, portanto, aloja-se na escolha dos temas a serem abordados pelos futuros jornalistas ${ }^{15}$.

\section{Tempo}

Do modo que nega a Bento Rodrigues uma inscrição jornalística de lugar, o Lampião aprisiona o subdistrito em um presente petrificado; lama que seca. 0 jornal não construiu memórias de Bento; não é possível, por meio do veículo, recuperar algo do que foi Bento, para além daqueles vestígios. Assim, o Lampião, até a edição 21, mal consegue construir um passado de Bento Rodrigues, e reporta apenas um vago pretérito: ligado à mineração. A mineração, aliás, é também o que determina o congelamento de Bento em um pretérito/presente que nunca permitirá um futuro (como lugar). Tal temporalidade, no Lampião, fortemente alicerçada na edição 21 , reporta - e documenta - um ex-lugar; a imagem do que não são (os bento-rodriguenses) mais (AUGÉ, 1994), em que o passado desapareceu completamente. Foi varrido.

Depois do rompimento da barragem, Bento surge ocupando toda a edição. Veiculado em 8 de dezembro de 2015, o número especial dedicou-se completamente à cobertura do rompimento da barragem, de uma perspectiva local; estritamente, Bento Rodrigues surge com destaque alto do meio do jornal ao fim, seguindo a linha editorial de afastar a edição da lama gradativamente até a última página. Na reportagem especial, Bento é foco no ato do rompimento e em algumas memórias de moradores:

A estudante Jennyfer Fialho dos Santos, 11, recorda com saudade a vida em Bento. Os fins de semana e a expectativa pela construção da piscina no quintal são memórias ainda muito vivas. [...] "Meu desejo é que façam um novo Bento, o mais parecido possível. Antes queria que melhorasse, porque lá tinha pouca coisa." (MELQUÍADES; VIERIA, 2015, p. 6)

O tempo de Bento nessa edição do Lampião é um tempo de rememoração; do pretérito. Tal lembrança é evocada tanto pelos personagens quanto pelo próprio discurso do

\footnotetext{
${ }^{15} \mathrm{O}$ processo produtivo adotado pelo jornal antes da transição para o modelo digital previa rotinas e etapas produtivas demarcadas: 1) apresentação editorial e pedagógica do jornal; 2) reunião de pauta geral; 3) reunião de editores para definir o espelho; 4) reunião de pauta fotográfica. Durante a produção, as equipes (em geral compostas de repórter+fotógrafo+diagramador) se reuniam semanalmente para trocar experiências, ajustar planejamento e executar tarefas conjuntas. A apuração era realizada no período das aulas, três por semana, e também em outros horários, dependendo das demandas. 0 fechamento era conduzido pelos editores com apoio dos professores e a participação de toda a equipe. Logo, a qualidade da produção também estava relacionada ao tempo que os estudantes tinham disponível para executar as tarefas.
} 
jornal: “José tenta seguir a vida com otimismo, mas as memórias do antigo Bento permeiam o pensamento. 'Às vezes não quero lembrar. Mas nos meus sonhos chega o freguês e fala, 'quanto é aquilo ali, Barbosa?'”.' (MELQUÍADES; VIERIA, 2015, p. 7). A reportagem menciona a falta d'água que atingida o lugar, e projetos realizados pela Samarco no subdistrito. Em outro bloco, a aposentada Maria Félix de Souza Santos recorda Bento. "Era um lugar muito sossegado, podia dormir com as portas abertas" [...] Nos últimos dois anos, o lugarejo estava diferente. Mais pessoas visitavam o local, as celebrações religiosas e a igreja estavam mais movimentadas." (MELQUÍADES E VIERIA, 2015, p. 7), diz a reportagem.

As 12 páginas transpiram majoritariamente o instante em que Bento foi destruído pela avalanche de rejeitos, desde um registro mais literal da lama, como demarca a capa (que congela um instante no tempo por meio da imagem de um relógio parado pela avalanche de lama) até uma projeção de futuro. Para tentar construir a presença que antes não havia, o jornal busca nas memórias, narradas a partir dos testemunhos da comunidade, as marcas do passado que sobraram, além de parcos mementos recuperados da lama. É a partir do presente de Bento - inexistência - que o Lampião investiga o passado do lugar - existência. Mais do que isso: é apenas porque Bento não mais existe, e o modo pelo qual não mais existe, que instiga a rememoração do lugar. Bento teve de desaparecer no mundo para ganhar existência e materialidade nas páginas do jornal. Porque agora são memórias, e não mais cotidiano, o veículo se dedica a falar de aspectos da comunidade que antes ignorou, como os festejos religiosos, a coxinha tradicional, a escola, o time de futebol.

Na ausência de registros imagéticos de Bento antes da tragédia, há o uso da ilustração, imagens em close, detalhes. E alguns planos abertos da área devastada. As histórias contadas referem-se a modos de ser da comunidade; a escola construída sobre fortes laços; o time de futebol; a igreja histórica; o bar da Sandra; a casa. Pequenos acontecimentos - o cotidiano de uma pequena comunidade que, no fluxo normal da vida nunca interessaram ao Lampião, mas que ganham espaço na noticiabilidade do jornal porque, agora, são marcados pela tragédia, rompidos pelo trauma: a escola destruída pela lama; as camisas e troféus perdidos do time; a igreja da qual só restou a fundação; o bar arrasado; a saudade da casa. De acordo com Seligmann-Silva, o trauma “[...] é caracterizado por ser uma memória de um passado que não passa. 0 trauma mostra-se, portanto, como o fato psicanalítico prototípico no que concerne à sua estrutura temporal." (SELIGMANNSILVA, 2008, p. 69).

À fotografia coube evidenciar pertences, objetos, detalhes que, no máximo, nos fazem imaginar o que restou de histórias nunca contadas pelo Lampião. A maior parte das fotos inclusive são feitas no distrito-sede, em Mariana, chegando ao ponto de caracterizá-la 
por um dos seus monumentos mais conhecidos, as igrejas da Praça Minas Gerais - uma delas aparece, de forma marcante, ao fundo da imagem de um dos personagens, um garçom cuja identidade é preservada. Aqui, a imagem de Bento é subsumida em Mariana. Não há nenhuma cena que mostre, insinue, destaque o que foi Bento, ou mesmo parte de seu cotidiano quando seus espaços eram habitados, experienciados, praticados pelos moradores agora expulsos pela lama. Em todo o jornal existe uma única cena de Bento antigo (Figura 10), a horta de um dos seus moradores, que embora não identificado pelo recorte atual dessa imagem, aparece na foto de seu arquivo pessoal, ao lado de uma menina, quando ele posa para a seção Ensaio. Na matéria da página 5 há outro mise en abyme ${ }^{16}$ que nos aproxima desses fiapos de passado: na imagem do/a manifestante, a pessoa carrega um cartaz com o que pode ser uma fotografia ou um desenho da Igreja de São Bento (Figura 11). No Lampião, são os próprios atingidos que inserem Bento imageticamente no jornal.

Figura 10 - Fotografia da página 12 da edição 21 do Lampião, que traz vislumbre de Bento Rodrigues

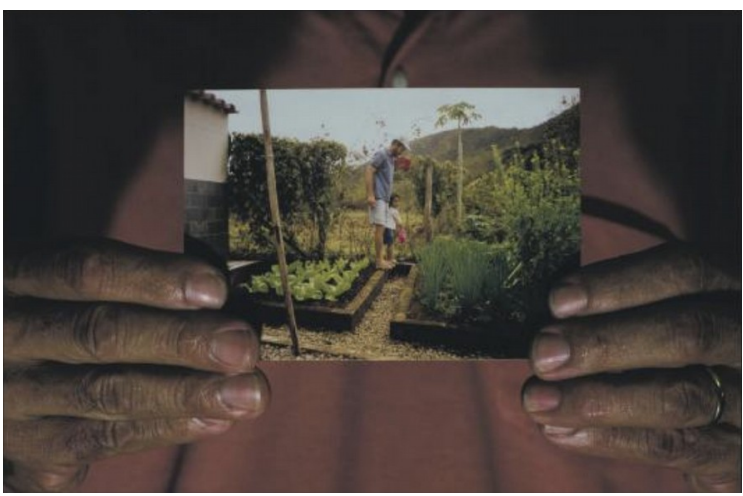

Fonte: Acervo digital do jornal Lampião no Issuu.

Figura 11 - Fotografia da página 5 da edição 21 do Lampião, com o que pode ser uma fotografia da

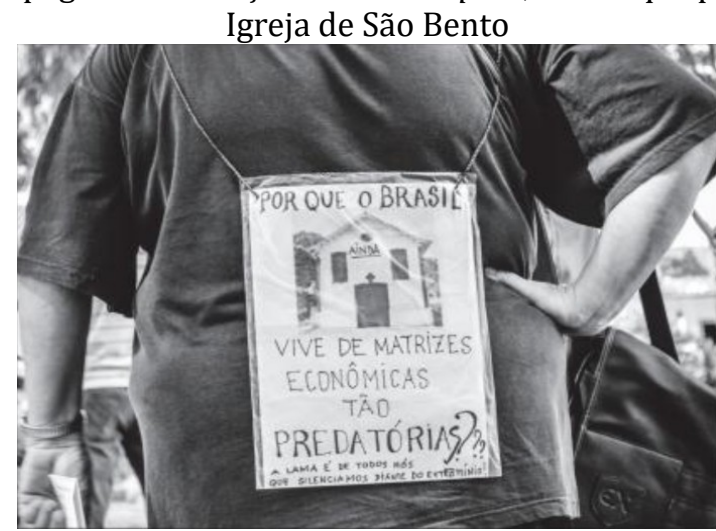

Fonte: Acervo digital do jornal Lampião no Issuu.com.

\footnotetext{
${ }_{16}$ "Textos que contenham uma ou mais duplicações que funcionam como espelhos ou microcosmos do texto", conforme Lucien Dallenbach e Annette Tomarken (DÄLLENBACH; TOMARKEN, 1980, p. 432, tradução nossa), ou que contenham repetições de aspectos importantes da narrativa em si mesmos, de acordo com Dällenbach e Tomarken (1980).
} 
Nesse sentido, ainda que o rompimento da barragem represente um acontecimentolimite, o inacreditável, a incredulidade como forma do acontecimento é mais afeita ao jornalismo que o novo - algo que não seja o impactante. A ruptura, aí, reside não em narrar a tragédia; mas em narrar o cotidiano, como na edição $22^{17}$, em que a única matéria sobre Bento refere-se à tentativa de preservação das festas religiosas do subdistrito (Vontade de superar perdas). “Ocorre, assim, que o jornalismo também opera em direção oposta à ideia de ruptura, promovendo a integração do 'novo' às categorias do já existente, como construído pelo sistema de informação e pela própria experiência social" (ANTUNES, 2007, p. 32), afirma Elton Antunes, que ressalta a estrutura arquetípica em um "[...] padrão que retém alguns acontecimentos e despreza outros [...] A desordem semeada pelo acontecimento, sua imprevisibilidade, é posta em um quadro contextual, em um mundo significado." (ANTUNES, 2007, p. 33). Se, do ponto de vista fenomenológico, o acontecimento é uma ruptura, e o rompimento de uma barragem é tal fenômeno disruptivo por excelência, no sentido midiático trata-se de um acontecimento típico que é estabilizado pelo jornalismo.

Do outro lado do espelho, o mundo já estabilizado de uma comunidade que (ainda) não havia sido destruída pelo rompimento pouco interessa/interessou a tal jornalismo. E, ao mesmo tempo, como essa comunidade nunca pertenceu ao lugar construído pelo Lampião, quando o jornal se debruça sobre ela, estabiliza também as tensões sociais que aquele lugar, como qualquer outro, enfrentou, e condensa Bento em um passado nostálgico e quase sem contradições. A ausência de Bento Rodrigues enquanto lugar no Lampião, aliada à sua presença (de uma ausência) marcante e plana depois de destruído, nos incita a questionar: que existência(s) interessa(m) ao jornalismo? De que maneira o jornalismo interdita a constituição midiática de lugares por meio de seu apagamento, da exclusão de suas narrativas?

\section{Presença/ausência}

Bento Rodrigues, destruído como consequência da atividade minerária (ou da corrupção desta), tem sua presença jornalística no Lampião também demarcada pela mineração. Antes de novembro de 2015, sua noticiabilidade esteve atrelada à mineração em metade das menções ao subdistrito feitas pelo veículo. Portanto, no jornal local que demandava explicitamente a presença dos distritos nas edições, não bastava ao distrito estar ali, naquele lugar; o cotidiano daquela comunidade não bastava para sua midiatização.

\footnotetext{
${ }^{17}$ Nas edições seguintes, a presença de Bento foi diversa. Na edição 23, a capa foi focada no município vizinho de Barra Longa e nas sequelas psicológicas que os moradores enfrentavam depois do rompimento da Barragem; na edição 24, uma matéria de página inteira traz o início do processo de reassentamento dos atingidos, no terreno de Lavoura.
} 
Há que se perguntar se o jornal era obrigado a estar no local; há que se perguntar também se, mesmo que não houvesse tal obrigatoriedade, a presença explícita de uma cobertura de distritos gerava uma expectativa de tal presença. Presença esta que era relacional; que se relaciona - e se subordina - a algo. No caso de Bento, à extração de ferro. A mineração determina, assim, o passado de Bento no jornal e consolida o presente que demarca a presença da ausência, amarrando os tempos midiáticos desse lugar/não lugar.

Mesmo com a mineração produzindo uma noticiabilidade subjacente, a presença de Bento é escassa. É como se proximidade e mineração não fossem suficientes para trazer esse lugar à tona; apenas a combinação com a catástrofe ${ }^{18}$, com o acontecimento-limite, foi capaz de fazer emergir Bento no Lampião - já como marcação de uma ausência, do que não é nem nunca mais será. Assim, se para Augé (1994) lugar é princípio de sentido para quem o habita e princípio de inteligibilidade para quem o observa, Bento nunca foi observado pelo jornalismo do Lampião. E, logo, não entendido. É um lugar midiático sem peso (AUGÉ, 1994).

As relações espaço-temporais que o veículo constrói em relação ao subdistrito evocam a interdição à legitimidade de Bento Rodrigues como um lugar, ou a exclusão de Bento do local a que o jornalismo do Lampião se refere, a realidade que o jornal constrói. E uma inexistência de um passado midiático para Bento: se esse lugar não existe (midiaticamente) nem nunca existiu, que memória dele o jornalismo há de construir? Ao contrário, o tempo eterno a que Bento está condenado no Lampião é o presente/passado, em que o subdistrito deixa de existir. Na articulação entre espaço e tempo, portanto, há uma dupla negação da existência jornalística e midiática de Bento Rodrigues no jornalismo local praticado pelo Lampião.

Outra questão a se pensar está na forma de se construir o jornalismo local, a partir da experiência, da vivência dos distritos e do cotidiano local; de uma inserção nas comunidades. Para se narrar com um pouco mais de propriedade, empatia e afeto histórias de lugares distantes da realidade do campus, ou dos distritos-sede de Mariana e Ouro Preto, talvez seja necessário praticar os espaços, os lugares, o dia a dia dessas comunidades, dessas localidades. Que só podem ser transformados em lugares a partir da resistência de desconstrução jornalística que faz deles não-lugares. Narrar um lugar é também construir percursos, conexões, identidades próprias que ressignifiquem suas ruas, suas praças, seus espaços de cotidianidade, suas histórias. É preciso, também, conciliar essa prática dos

\footnotetext{
${ }^{18}$ De acordo com Amaral (2013), a catástrofe é “[...] por definição, um evento que provoca trauma, outra palavra grega, que significa 'ferimento'." (AMARAL, 2013, p. 75); contemporaneamente, a catástrofe é uma experiência que tem seu valor culturalmente definido de acordo com aquilo que destrói, com sua magnitude. 0 rompimento da Barragem do Fundão tem sido classificado como a maior catástrofe socioambiental do Brasil, com ênfase na questão ambiental, o que dá a dimensão de seu caráter destruidor.
} 
espaços com as demandas do ensino formal universitário, constituído de créditos, disciplinas, horários, tempos de estudo.

A partir do estudo das marcações de Bento Rodrigues no Lampião - ausência e presença de uma ausência - percebemos que trata-se de um jornalismo local voltado mais às sedes dos municípios, sem olhar para além, para o que as circunda - justamente as comunidades que recebem menos atenção do poder público, da mídia em geral; comunidades midiaticamente invisíveis. Trata-se de um movimento que pode ser interpelado em termos da qualidade de seu experimentalismo e do quanto se distancia ou se aproxima do jornalismo de referência, que também não deu espaço a Bento enquanto o lugar existia. A ode de José Saramago à investigação e à experiência aos 45 minutos de Janela da Alma (2001) nos parece apropriada para pensar um jornalismo local que não se furte a mapear os territórios que se dispõe a reportar, e aos quais se reporta: "Para conhecer as coisas, há que dar-lhes a volta. A volta completa” (JANELA DA ALMA, 2001).

\section{Referências}

AMARAL, Márcia Franz. Os testemunhos de catástrofes nas revistas brasileiras: do medo individual à patemização midiática. Contracampo, Niterói, v. 26, n. 1, p. 71-86, 2013.

ANTUNES, Elton. Temporalidade e produção do acontecimento jornalístico. Em Questão, Porto Alegre, v. 13, n. 1, p. 25-40, 2007.

AUGÉ, Marc. Não-lugares: introdução a uma antropologia da supermodernidade. Campinas: Papirus, 1994.

BARDIN, Laurence. Análise de conteúdo. Lisboa: Edições 70, 2004.

BAUMAN, Zygmunt. Comunidade: a busca por segurança no mundo atual. Rio de Janeiro: Jorge Zahar, 2003.

BRASIL. Presidência da República. Pesquisa brasileira de mídia 2015: hábitos de consumo de mídia pela população brasileira. Brasília: Secom, 2014.

CAMPONEZ, Carlos. Jornalismo regional: proximidade e distanciações: linhas de reflexão sobre uma ética da proximidade no jornalismo. In: CORREIA, João Carlos (org.). Ágora: jornalismo de proximidade: limites, desafios e oportunidades. Covilhã: Livros LabCom, 2012. p. 35-48.

CERTEAU, Michel de. Invenção do cotidiano: artes de fazer. 3. ed. Petrópolis: Vozes, 1998.

DÄLLENBACH, Lucien; TOMARKETN, Annette. Reflexivity and Reading. New Literary History, Baltimore, v. 11, n. 3, p. 435-449, 1980.

DORNELLES, Beatriz. Características do jornalismo impresso local e suas interfaces com jornais comunitários. Contracampo, Niterói, n. 14, p. 163-178, 2006. 
HELLER, Agnes. 0 cotidiano e a história. 11. ed. São Paulo: Paz e Terra, 2016.

GOOGLE MAPS. 0 que é o Street View? [S.l.]: Google, [2018]. Disponível em:

https://www.google.com.br/intl/pt-PT/streetview/apps/. Acesso em: 15 fev. 2018.

GROTH, Otto. 0 poder cultural desconhecido: fundamentos da ciência dos jornais. Petrópolis: Vozes, 2011.

JANELA da Alma. Direção: João Jardim e Walter Carvalho. Produção: Claudia Braga, Bia Castro, Isa Castro, João Jardim, Flávio Tambellini e Mayanna von Ledebur. [S.l.]: Brazil Telecom, 2001. DVD (73 min.), son., p \& b.

OUTRO jornalismo é possível. Lampião, Mariana, ano 1, n. 0, p. 2, maio 2011.

MANDARINO, Jackie. Do plantio aos resultados. Lampião. Mariana, p. 9-9. out. 2014. Disponível em: <https://issuu.com/jornallampiao/docs/lampiao_ed16_web_1_>. Acesso em: 13 jun. 2019.

MELQUÍADES, Agliene; VIEIRA, Ana Carolina. Fragmentos de uma tragédia marianense. Lampião, Mariana, ano 6, v. 21, p. 6-7, 18 dez. 2015.

MARIANA. Prefeitura. Prefeitura de Mariana. Distritos de Mariana. 2019. Disponível em: <http://www.mariana.mg.gov.br/todos-distritos>. Acesso em: 31 maio 2019.

MARIANA. Minas da passagem. Mariana: Nossa Senhora de Caravaggio Empreendimentos, 2018. Disponível em: http://minasdapassagem.com.br/visitacao.html. Acesso em: 1 fev. 2018.

MINAS GERAIS (Estado). Lei Complementar no 37, de 18 de janeiro de 1995. Dispõe sobre a criação, a incorporação, a fusão e o desmembramento de municípios e dá outras providências.. Minas Gerais Diário do Executivo. 19/01/1995. ed. Belo Horizonte, MG.

NEVEU, Érik. Sociologia do jornalismo. São Paulo: Edições Loyola, 2006.

NOGUEIRA, Aline. Turismo requer atenção. Lampião. Mariana, p. 3-3. dez. 2014. Disponível em: <https://issuu.com/jornallampiao/docs/lampi_o_ed_17_web1>. Acesso em: 13 jun. 2019.

OLIVEIRA, Francielle. Escola incentiva crianças a terem pensamento crítico. Lampião. Mariana, p. 5-5. jun. 2015. Disponível em: <https://issuu.com/jornallampiao/docs/lampi_o_19>. Acesso em: 13 jun. 2019.

EÇA DE QUEIROZ, José Maria. As catástrofes e as leis da emoção. In: Cartas familiares e bilhetes de Paris. Porto: Lello Editores, 1979. Disponível em: http://www.dominiopublico.gov.br/download/texto/eq000003.pdf. Acesso em 10 de fevereiro de 2018.

RIBEIRO, Joaquim. A imprensa regional e as comunidades locais Jornal Alvorada: caracterização de um quinzenário local do concelho da Lourinhã. 2010. Dissertação (Mestrado em Antropologia) - Escola de Ciências Sociais e Humanas, Instituto Universitário de Lisboa, Lisboa, 2010. 
SANTOS, Ana Carolina Lima; GOMES BARBOSA, Karina; AQUINO, Talita Iasmin Soares.

Lampião: apresentação. Mariana: [s.n.], 2016. 29 diapositivos, color.

SELIGMANN-SILVA, Márcio. Narrar o trauma: a questão dos testemunhos de catástrofes históricas. Psicologia clínica, Rio de Janeiro, v. 15, n. 2, p. 65-82, 2008.

SENA, Leandro. Obras no aterro sanitário da cidade correm contra o tempo. Lampião. Mariana, p. 9-9. out. 2011. Disponível em: <https://issuu.com/jornallampiao/docs/ed3>. Acesso em: 13 jun. 2019.

SILVA, Gislene. Para pensar os critérios de noticiabilidade. In: SILVA, Gislene; SILVA, Marcos Paulo da; FERNANDES, Mario Luiz (org.). Critérios de noticiabilidade: problemas conceituais e aplicações. Florianópolis: Insular, 2014.

UFOP. Projeto Pedagógico do Curso de Jornalismo. Mariana: [s.n.], 2015.

VARÃO, Rafiza. Sobre clássicos, tradição e o campo comunicacional. Estudos em Comunicação, Covilhã, v. 5, p. 227-239, maio 2009.

VIEIRA JUNIOR, Antônio. Uma pedagogia para o jornal-laboratório. 1980. Tese (Doutorado em Comunicação) - Escola de Comunicações e Artes, Programa de pósgraduação em Ciências da Comunicação, Universidade de São Paulo, São Paulo, 2002.

\title{
Place and time: Bento Rodrigues at Lampião
}

\begin{abstract}
We sought to investigate the presence of Bento Rodrigues, a sub-district of Mariana (MG), in local marianense journalism prior to the collapse of the Fundão Dam on November 5th, 2015, which devastated it, and if - and how - that presence changed after the catastrophe. Our research object is the newspaper Lampião, which carries the double characteristic of local and experimental journalism. The researched corpus is composed of the 21 editions prior to the tragedy - from 0 to 20 - and the 21st edition, dedicated to the event. Using content analysis, we work with the inference variables of space and time to demarcate presences and absences of "Bento" as a place; articulate the temporalities engendered by the vehicle's coverage; and reflect on the newsworthinesses triggered by the newspaper to bring the sub-district to the surface or to interdict its media existence, in this double local-experimental registry. From the analysis, we conclude that Bento's past in the newspaper is determined by mining activity, which also consolidates a present that marks presence of absence, tying midiatic times of this place/non place.
\end{abstract}

\section{Keywords}

Bento Rodrigues. Local Journalism. Lampião. Time. Place. 